\title{
Corruption in a Tax Game
}

\author{
M. Adnan Kabir \\ University of Liberal Arts Bangladesh
}

\author{
Nazia Choudhury \\ University of Liberal Arts Bangladesh
}

\author{
Liliping \\ University of Liberal Arts Bangladesh
}

\begin{abstract}
Our inability to fully predict the complexity of tax behavior stems from the fact that tax evasion, by its very nature, is difficult to observe. The illegality of underreporting taxable income generates the need to maintain secrecy which makes it all the more strenuous to isolate the factors that influence wealth disclosure to tax officials. This paper is an experimental tax game in the context of Bangladesh where a culture of corruption permeates. In particular, this research intends to investigate individuals' behavior when they have an incentive to partake in corruption by evading taxes through paying bribes. The study finds that individuals readily choose the financially lucrative and payoff maximizing option of paying bribes, whenever possible, to mitigate the risks of getting caught. We also find that, more often than not, higher tax rate decreases wealth disclosure. Moreover, there is considerable evidence that enforcement of punishment, through the use of audits, acts as a deterrent when it comes to under-reporting wealth.
\end{abstract}

Keywords: corruption, Tax game, wealth disclosure

\section{INTRODUCTION}

All economies of the world, be it small or large, are susceptible to corruption in one form or another. "It is a phenomenon that is apparent throughout human history" (Dong et al., 2012, p. 609). Ever since the dissolution of the Soviet Union during the 1990's, the issue of corruption in governance and all other facets of social life has been extensively studied and debated. In addition, liberalization of the media and globalization of economies and politics have played a major role in raising awareness and accountability of this pervasive issue (Abbink et al., 2002). The advent of corruption on a global scale creates distortion in all aspects of economic decision making. Corruption is more widespread in developing economies than developed economies (Svensson, 2005; Olken \& Pande, 2012). To address the issue of corruption in developing economies, international organizations have undertaken various enterprises over the years such as the anti-corruption initiatives of Organisation for Economic Co-operation and Development (OECD), UNDP and World Bank (Olken \& Pande, 2012). So, the issue of corruption has been well studied in academic literature and incorporated into policymaking. Several research and experiments have been conducted by economists and physiologists alike to single out factors that contribute to corruption 
that includes socio-economic and institutional motivations. In examining corruption and its varied nature, researchers have found that it has a strong correlation with societal practice of peers. Social norms and values partly influence the behavior of individuals when it comes to engaging in corruption (Barr \& Serra, 2010). In other words, corrupt behavior is not fully inherent as individuals may be heavily influenced by the perceived activities of others (Dong et al., 2012).

One of the definitions of corruption, as defined by the World Bank (1997), is the abuse of public office for private gains. Bribes are a major facilitating tool of corruption used by private entities to get governmental favor in securing government contracts, benefits, lower taxes and licenses. Corruption creates an environment for tax evasion, as corrupt officials look for opportunities to increase their income through bribes (Alm et al., 2016). Although in an ideal world we expect everyone in a civilized society to pay their share on taxes, this is far from true (Chowdhury, 2015). In a report published by Transparency International, Nawaz (2010) inferred that there is consensus among researchers on the significant negative impact on tax revenues due to corruption. Wherever taxes are imposed, there are entities that will try to avoid them, and this problem is more systemic in developing countries because of low accountability standards (Flatters \& Macleod, 1995). Conversely, a higher tax rate acts as an incentive for tax evasion in any economy. Tax compliance and tax evasion have also been well studied in the literature (Alm et al., 1992; Akdede, 2011). Cummings et al. (2005) designed laboratory experiments in different countries and concluded: "tax compliance level can be explained by differences in the fairness of tax administration, in the perceived fiscal exchange, and in the overall attitude towards the respective governments" (p. 2). Wenzel (2005) iterated similar sentiments by concluding that the complex role of individual ethics and social norms explain individuals' taxpaying behavior. Moreover, tax noncompliance behavior can be partly explained by sources of income, attitude, perception, and knowledge of taxes (Saada, 2012).

Corruption and tax evasion problems have special significance in the context of Bangladesh. Despite corruption in every sector, its economy has been one of the fastest growing in the world (World Bank, 2019). Its economy has been projected to expand above 7.0 percent per year with the aid of strong fixed investment, vigorous private consumption and accommodative monetary policy (United Nations, 2019). However, maintaining the pace of economic growth is a challenge for the country as it needs to continuously work on the reform of its economic sector. Studies such as Nurunnabi (2019), highlights that part of the economic reform of Bangladesh includes the need to look at its tax system and institutional framework as total tax revenue as a percentage of GDP has been the lowest in South Asia for the past 17 years. Such sentiments were also shared by Ahmed (2018), who iterates the seriousness of the tax evasion problem in Bangladesh and concludes that a strong tax culture and political will are essential in combating this issue. Bangladesh only taxes 43 percent of its potential taxable revenue (Fenochietto \& Pessino, 2013). If Bangladesh is to fulfill its optimistic economic landmarks such as attaining Sustainable Economic Goals, it must rely on and efficiently manage its taxes. Thus, a close examination of the tax behavior of individuals could benefit the country in addressing its tax compliance issues. Simply increasing auditing and penalties may be ineffective and a fundamental revision of checks and balances may be required. Despite the efforts of the National Board of Revenue (NBR) Bangladesh, tax evasion has not improved much as citizens continue to outright refuse to pay taxes or take advantage of loopholes in an attempt to underpay taxes (Report, 2019). The problem of tax evasion is especially hurtful for the Bangladesh economy as the government is ill-equipped to lose potential funds. Corruption between taxpayers and tax collectors have detrimental effects on government revenue collection. Taxpayers are more likely to evade taxes when they find their unlawful actions have no impact on public sector output. Hence, indirect taxes may be an option in poor developing countries to reduce unlawful cooperation between taxpayers and tax collectors (Jellal \& Bouzahzah, 2012).

This paper intends to address this problematic issue by determining whether economic motivations of maximizing payoffs can be an explanation of why individuals choose to engage in corrupt behavior. Studies pertaining to corruption and tax issues in Bangladesh have mainly focused on causes, challenges, implications, and remedies (Sen \& Bala, 2002; Mahmood, 2010; Bhuiyan, 2012). However, studies that specifically observe behavior in an experimental setting in Bangladesh are non-existent in the literature. We thus attempt to examine, in an experimental setting, how individual behavior plays out in the context 
of tax compliance. This important socio-economic question is extremely relevant in the context of governance as tax compliance is directly associated with governments' revenue and fiscal policy. Although this study defines corruption as the inclination towards tax evasion, it does give us a general idea as to how individuals make economic decisions when faced with options. As this taxpaying game can, in some ways, be attributed to a gambling game, we give subjects the option to eliminate the notion of 'gambling' by quantifying the risk through the inclusion of voluntary bribe payment. We designed the tax game to test how individuals act when given the opportunity to maximize payoffs. The nature of the game will help us understand whether corruption plays a pivotal role in economic decision making and the psychology behind authoritative compliance in the face of ethical loopholes. Central to our thesis are two intertwined legacies that are the hypotheses the study attempts to validate.

\section{Hypothesis 1: Wealth disclosure decreases when the tax rate increases.}

Hypothesis 2: Wealth disclosure increases when there are possible audit and penalty threats.

The intuition behind hypothesis 1 is a general understanding that stems from the risk-return matrix. When taxes are high, the payoff from hiding wealth may justify the risk. This tax rate and wealth disclosure relationship is best described by the "Laffer Curve". This famous term coined by Jude Wanniski, refers to Arthur Laffer's explanation of the tax rates and tax revenue relationship. The Laffer Curve says that government revenues are zero when the tax rates are 0 and 100 percent. The tax revenue increases when the tax rate rises from 0 percent and peaks at an optimal tax rate. Beyond this point, the tax revenue keeps falling as the tax rate increases, to the point where a 100 percent tax rate brings in no revenue at all. In other words, the tax revenue is generally a symmetric bell-shaped distribution in relation to the tax rate (Wanniski, 1978). The study adopts this logic to test the influence of tax rate on wealth disclosure. The tax game is thus played in three rounds, where the tax rate in round 1, 2 and 3 are 40,60 and 80 percent respectively. The rounds are played in four successive 'Treatments', where the notion of tax audit and bribery is factored in. This mechanism is geared towards testing the validity of Hypothesis 2 as it is generally understood that the risk of audit acts as a deterrent of wealth under-reporting. Segregation of different treatments will mean subjects have to weigh between incentive and punishment before disclosing their wealth. The design of the experiment also has a provision for participants to eliminate the risk of being caught should they choose to indulge in corruption and bribe their way into an economic advantage. This inclusion of bribery to mitigate risks of punishment does have real-world connotations. Generally speaking, greater negative externalities reduce individuals' propensity to engage in bribery (Barr \& Serra, 2010). The existence of this relationship between business tax evasion and taxrelated bribes have been documented in the literature (Joulfaian, 2009). No governing institution, even corrupt regimes, openly advocate tax evasion. For corrupt governments, tolerance of tax evasion only comes at the expense of paying bribes to officials. Penalty, as well as awareness of offenses, have a significant effect on tax compliance. If individuals have knowledge of tax evasion and its consequences, their tax evasion activities might decrease (Modugu \& Anyaduba, 2014). In surveys conducted by Mohdali et al. (2014), a clear connection was observed between tax evasion and tax audits. People tend to comply with wealth disclosure rules when they receive audit and penalty threats. Similar to the general consensus in the literature, this study finds similar patterns of tax evasion when the tax rate increases, and wealth disclosure increases when not doing so becomes risky.

\section{LITERATURE REVIEW}

The advent of corruption is a growing major economic problem around the world which had led to a growing interest in the empirical analysis of its causes and consequences. In recent years, significant progress has been made in academia to study this phenomenon using statistical analysis of field data (Abbink et al., 2002). Adherence to corruption is intended to maximize self-interest and payoffs, which corrupt entities view through a lens of economic rationality. Long \& Rao (1995) showed that, in the 
context of a firm, after corrupt behavior is discovered the value of a firm significantly decreases. Corrupt practices are heavily influenced by the role of social norms (Kubbe \& Engelbert, 2017). Barr \& Serra (2010) explains how a culture of corruption exists and persists in some economies to the point where the idea of corruption is a social norm. The study further claims, such cultural values "justify and guide the ways that social institutions function, their goals and modes of operation" (p. 1).

Numerous studies have been conducted to understand the rationale behind the diversity in individuals' tax compliance decisions. This issue is not particularly new to the academic literature as early studies, such as Allingham \& Sandmo (1972), reported how individuals employ conventional expected utility theory to benefit from tax avoidance by weighing the risk of being exposed. They concluded, individuals prefer to evade or minimize their tax payments if they know the chances of getting caught are low. Consequent studies employed similar expected utility theory models to explain individuals' tax evasion behavior (Wang \& Conant, 1988; Crocker \& Slemrod, 2005; Goerke \& Runkel, 2006). Not all individuals look to under-report taxes in order to maximize payoffs, as individuals, in many cases, overestimate the risk of detection and punishment. Moreover, these individuals often value government provisions paid by taxes (Alm et al., 1992).

A quintessential example of corruption is tax administrators accepting bribes from taxpayers to pursue an illegal gain. If the bribe amount set by government officials is excessive or higher than an optimal amount that does not justify the payoff, individuals prefer not to evade taxes (Akdede, 2011). Joulfaian (2009) delineated that positive relation exists between business tax evasion and tax-related bribes by studying data from a sample of businesses in 26 transition economies in the former Soviet Union and Turkey. Acconcia et al. (2003) showed that higher penalty charges for tax avoidance could induce individuals to comply with tax laws. On the other hand, a higher penalty for corruption could reduce corruption at the expense of tax compliance. Additionally, Bordignon (1993) came up with several factors that have an impact on individuals' inclination of dodging taxes. First, higher tax rates are positively associated with more tax evasion. Second, the government's lack of interest to manage efficient allocation of public expenditure to provide public goods and services leads to more tax evasion. Mauro (1998) made a similar claim by establishing a link between corruption and government expenditure. Tax administrators in corrupt societies intend to magnify their income via bribes which eventually tend to encourage higher tax evasion by firms. Firms weigh the cost of paying or evading taxes, via bribery to tax officials, when it comes to complying with tax law (Alm et al., 2016).

The problem of tax evasion for a country like Bangladesh may have a cultural component. According to a research by McGee et al. (2016), there is strong evidence that some cultures accept tax evasion as ethically correct and some believe that it is okay to equivocate taxes under specific circumstances. The ethical ground for tax evasion depends on several factors: fairness of the tax system, government corruption level or any other unethical act by the government such as human rights abuse. Tax compliance increases when the tax amount is reasonable or when citizens perceive that the government is doing justice with tax money by investing in commendable projects (McGee et al., 2012). In some countries, tax evasion attitude is encouraged as it is seen by society as a negligible offense (Hofmann et al, 2008). Such literature should resonate with the cultural dynamics of Bangladesh, as Knox (2009) states that the public trust of government officials of Bangladesh is notably low due to perceived corruption. Even under the implementation of punishments such as penalties and tax audits, taxpayers do not fully comply with wealth disclosure when enforcement of laws are not strictly maintained (Okoye et al., 2012). Corruption in Bangladesh prevails at all levels of society, the rule of law is weak, and most institutions lack transparency (Wickberg et al., 2012), which may explain the abysmally low tax revenue. Fenochietto \& Pessino (2013), in a comprehensive study of the tax effort and tax capacity of 113 countries, found that oil-rich countries have a low ratio of tax revenue to the potential taxable base. As expected, corrupt countries are the ones to lose out most from their tax potential. In an act of desperation, National Board of Revenue (NBR) Bangladesh conducted surveys in 2019 among eligible taxpayers and university students, urging them to register as voters in an attempt to bring additional people under the tax net. Although perceived to be successful, it was still a relatively small number in comparison to the potential tax base of the country (Report, 2019). Each year, NBR struggles to achieve its annual goal of revenue collection in 
spite of its numerous efforts to motivate individuals and institutions to submit their tax returns. Due to the fact that governments have imperfect ability to monitor the behavior of its tax officials, the severity of the problem is more in developing countries where accounting and bookkeeping standards are low (Flatters \& Macleod, 1995).

\section{EXPERIMENT DESIGN}

The game consists of 64 participants from Bangladesh. Before starting the game, all the instructions were provided, and the nature of the game was explained. There was a short round of question-answer session at this stage. To reduce confirmation bias, the participants were not allowed to communicate with each other in any way once the game started. At first, they were demonstrated a practice round to familiarize themselves with the nature of the experiment. The game was played chronologically, meaning treatment 1 first, followed by treatment 2 and so on. The risk of under-reporting wealth increases after each consecutive treatment. The decisions of the participants were confidential as we intended to replicate a real-world scenario. Announcing the results to everyone would create the risk of external judgmental insecurity and other physiological annotations which may skew our findings. Participants were reassured that the choices they make would remain anonymous to everyone except the experiment coordinators. Table 1 shows how the framework of the game and treatments are subcategorized into rounds for analysis and computational ease.

TABLE 1 ROUNDS AND TREATMENTS

\begin{tabular}{|c|c|c|c|}
\hline Treatment \& Round & Round 1 & Round 2 & Round 3 \\
\hline Tax rate (\%) & 40 & 60 & 80 \\
\hline Treatment 1 & \multicolumn{3}{|c|}{ No audit. No bribe } \\
\hline Treatment 2 & \multicolumn{3}{|c|}{ Audit. Bribe can be paid after Audit } \\
\hline Treatment 3 & \multicolumn{2}{|c|}{ Audit. Bribe has to be paid before Audit } \\
\hline Treatment 4 & \multicolumn{2}{|c|}{ Audit. No bribe } \\
\hline
\end{tabular}

Participants were endowed BDT $100^{1}$ at the start of each round and no money was carried off to the next round. After the participants were seated and instructed, they were asked one at a time to proceed to a private room where there was a set of marked lockers. A marked key was provided before they entered the room with which they could open the corresponding marked locker. Inside the locker they were given a large envelope containing a colored chip, a pen, a small piece of paper and a small envelope. The small envelope contained the initial endowment of BDT 100. Participants were told to keep the amount of money that they wanted to report in the small envelope, meaning if they intended to report half of their income then they should keep BDT 50 in the small envelope. The amount of money they intended to hide should be kept inside the large envelope. Then as per instructions, they kept the colored chip and returned to their designated seat until they were called again for further rounds. The transactions were recorded by a recorder after each round. Figure 1 shows the contents of the large envelope. 


\section{FIGURE 1 \\ CONTENTS INSIDE ENVELOPE}

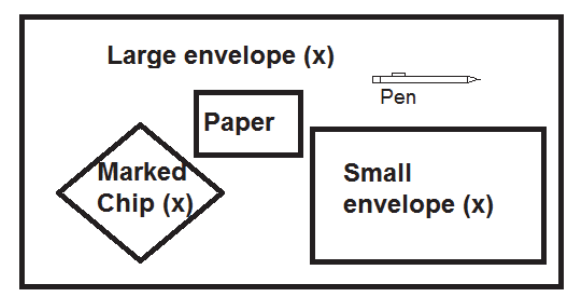

The purpose of the marked chip was to determine if the participant would be audited. After the experiment, subjects picked a chip from a box which was later used to determine if they fell under audit. The probability of being audited is 25 percent which pertains to Treatment 2, 3 and 4 . The paper and pen were given for subjects to write down "Yes" if they intended to pay bribe. We used loaded instructions and did not shy away from using terminology that were straightforward. Participants were asked to replicate a real-world scenario to the best of their ability. Participants would get to keep the amount of money they earn from all the rounds of the game. No participation fees were provided as payoffs from the rounds are intended as compensation for participating in the game. A monetary incentive was there to cheat on income reporting as no other additional fees were paid. It must be kept in mind that participants had the option of at least coming out with a risk-free earning, which was the money left over after paying the required taxes.

\section{Treatments and Payoff functions}

Treatment 1

The first treatment, like all the other treatments, consists of three rounds. Here, subjects will report their endowed wealth without any probability of being audited. The treatments were designed in such a way that the risks of under-reporting wealth increases from one treatment to the next. Without the existence of audit, there is no need for an option to pay any bribe in this treatment. Treatment 1 is the most riskless treatment and would effectively work as our control treatment to judge participants' perception of tax evasion against other treatments. This specific treatment intends to test the compliance of participants when the threat of punishment was nonexistent. Any compliance here would be merely ideological as rational and utility maximizing subjects would be left to their own ethical judgment.

The subject's expected payoff from under-reporting wealth from this treatment would be

$$
\begin{aligned}
\Pi_{\mathrm{T} 1 \mathrm{Rj}} & =\omega-\theta \\
& =100-\theta
\end{aligned}
$$

Where $\Pi_{T 1 R j}$ denotes the payoff from Treatment 1 and Round ' $j$ '. The initial endowed wealth at the beginning of the round is denoted by ' $\omega$ '. $\theta$ is the amount of income reported. The expected payoff here is a straightforward one where under-reporting leads to a riskless payoff. Payoff maximizing ethos would dictate this treatment will have minimal compliance across all the rounds. The tax rate in Round 1 is relatively low and chosen such that we could analyze how subjects react to progressive tax rates. The Round 1 tax rate is very reflective of a more practical tax rate setting. Round 2 raised the stakes a little higher with a tax rate of $60 \%$. This is certainly not a financial exaggeration as its applicability in the real world is probable. For Round, 3 we up the ante to $80 \%$. This might not have a strong practical connotation but is important to the dynamics of the study. We intended to test how participants react to such financial constraints. 


\section{Treatment 2}

In Treatment 2, the concept of bribe is factored in. The bribe here is a fixed payment of BDT 50. Payment of the said bribe, denoted by $\beta$, would eliminate the possibility of fine even if subjects are caught in an audit underreporting their income. However, bribe is optional here meaning subjects have an option to pay the bribe after the audit. This gives them a chance to avoid the hefty fine and, if lucky, also the bribe amount. ' $\mathrm{P}$ ' indicates the probability of being audited. In retrospect, $(1-\mathrm{P})$ implies the probability of not being audited. Putting bribe and audit into perspective the expected payoff equation would be

$$
\begin{aligned}
\Pi_{\mathrm{T} 2 \mathrm{Rj}} & =\mathrm{P}(\omega-\theta-\beta)+(1-\mathrm{P})(\omega-\theta) & \text { if } \theta \neq \omega, 0 \text { otherwise }(2) \\
& =87.5-\theta &
\end{aligned}
$$

\section{Treatment 3}

Treatment 3 is similar to Treatment 2 except the fact that bribe has to be paid before audit to avoid fine. There is no option to pay bribe after the audit, so participants have to contemplate the risks of possible unavoidable repercussions for under-reporting income. The monetary value of the bribe stays the same at BDT 50. Payment of the said bribe before audit would eliminate the possibility of fine even if subjects are caught underreported their income. Should the participants choose not to pay a bribe and be caught under-reporting their income, they have to pay a hefty fine which is 15 times the amount they underreport. Thus, this number may vary among participants as greedy participants will be punished more harshly.

The expected payoff equation from under-reporting would be

$$
\begin{aligned}
\Pi_{\mathrm{T} 3 \mathrm{Rj}} & =\mathrm{P}[(\omega-\theta)(-15)]+\mathrm{P}(\omega-\theta-\beta)+(1-\mathrm{P})(\omega-\theta)+(1-\mathrm{P})(\omega-\theta-\beta) \quad \text { if } \theta \neq \omega, 0 \text { otherwise (3) } \\
& =2 \theta-250
\end{aligned}
$$

The expected payoffs from under-reporting wealth is clearly not worth it and does not warrant the risk as equation (iii) shows, even fully disclosing wealth does not have a positive expected return. This implies an optimizing participant would pay the bribe before the start of the treatment.

\section{Treatment 4}

Treatment 4 becomes a more restrictive Treatment as the option to bribe is eliminated. Any participant who is audited will have to pay the fine. Rational optimization would dictate, this treatment will show high levels of wealth disclosure.

$$
\begin{aligned}
\Pi_{\mathrm{T} 4 \mathrm{Rj}} & =\mathrm{P}[(\omega-\theta)(-15)]+(1-\mathrm{P})(\omega-\theta) \\
& =3 \theta-300
\end{aligned}
$$$$
\text { if } \theta \neq \omega, 0 \text { otherwise (4) }
$$

\section{RESULTS AND ANALYSIS}

The breakdown of average wealth disclosure across all Treatments, denoted by ' $T$ ', and rounds, denoted by ' $R$ ' are shown in Table 2. $T 1$ indicates data from Treatment $1, \mathrm{R} 1$ indicates data on wealth disclosure of all Round 1s and T1R1 indicates data from Treatment 1 Round 1. The rest follows the same intuitive logic.

The first issue that needs to be addressed is the existence of statistical differences between the Rounds and Treatments. Table 3 shows a comprehensive analysis of statistically significant differences across wealth disclosure of all Treatments and Rounds. Analysis of variance (ANOVA) is computed among Rounds, among Treatments and among Rounds of each Treatment separately, all of which are labelled. The p-values indicate there are indeed statistical differences between the mean wealth disclosures with the exception of Treatments 2 and 4. The same is reflected in Bartlett's test for equal variances. It is used to test whether multiple samples have homogeneity of variances (Lim \& Loh, 1996; Snedecor \& Cochran, 1989). The implication behind Treatment 2 could be that the inclusion of bribe has made the existence of 
tax rates redundant. And in case of Treatment 4, participants could be more worried about contemplating the steep punishment if audited than about the tax rate. The hypothesis test represented by ANOVA is detailed in the Appendix.

TABLE 2

DESCRIPTIVE STATISTICS

\begin{tabular}{|cccccc|}
\hline Variable & Obs & Mean & SD & Min & Max \\
\hline T1R1 & 64 & 24.22 & 30.67 & 0 & 100 \\
T1R2 & 64 & 19.9 & 25.91 & 0 & 100 \\
T1R3 & 64 & 12.28 & 18.15 & 0 & 70 \\
T2R1 & 64 & 25.53 & 27.34 & 0 & 100 \\
T2R2 & 64 & 20.92 & 22.23 & 0 & 80 \\
T2R3 & 64 & 17.36 & 19.99 & 0 & 70 \\
T3R1 & 64 & 40.29 & 26.86 & 0 & 100 \\
T3R2 & 64 & 33.18 & 21.06 & 0 & 100 \\
T3R3 & 64 & 28.39 & 20.92 & 0 & 95 \\
T4R1 & 64 & 50.06 & 31.94 & 0 & 100 \\
T4R2 & 64 & 48.01 & 30.6 & 0 & 100 \\
T4R3 & 64 & 46.42 & 31.86 & 0 & 100 \\
R1 & 64 & 140.09 & 94.39 & 0 & 400 \\
R2 & 64 & 122 & 71.58 & 0 & 290 \\
R3 & 64 & 104.45 & 55.2 & 0 & 255 \\
T1 & 64 & 56.4 & 67.51 & 0 & 215 \\
T2 & 64 & 63.81 & 64.74 & 0 & 215 \\
T3 & 64 & 101.85 & 61.76 & 0 & 270 \\
T4 & 64 & 144.48 & 89.59 & 0 & 300 \\
\hline
\end{tabular}


TABLE 3

ANALYSIS OF VARIANCE (ANOVA)

\begin{tabular}{|c|c|c|c|c|c|c|c|}
\hline \multicolumn{2}{|c|}{ Source } & Rounds & $\begin{array}{c}\text { All } \\
\text { Treatments }\end{array}$ & $\begin{array}{c}\text { Treatment } \\
1\end{array}$ & $\begin{array}{c}\text { Treatment } \\
2\end{array}$ & $\begin{array}{c}\text { Treatment } \\
3\end{array}$ & $\begin{array}{c}\text { Treatment } \\
4\end{array}$ \\
\hline \multirow{3}{*}{ 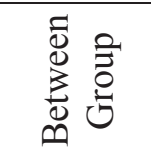 } & SS & 10167 & 104801 & 4675 & 2148 & 4590 & 425 \\
\hline & $\mathrm{df}$ & 2 & 3 & 2 & 2 & 2 & 2 \\
\hline & MS & 5083 & 34934 & 2338 & 1074 & 2295 & 213 \\
\hline \multirow{3}{*}{ 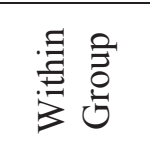 } & SS & 620347 & 525712 & 122298 & 103411 & 100965 & 187196 \\
\hline & $\mathrm{df}$ & 765 & 764 & 189 & 189 & 189 & 189 \\
\hline & MS & 811 & 688 & 647 & 547 & 534 & 990 \\
\hline \multirow{3}{*}{$\stackrel{\pi}{0}$} & SS & 630514 & 630514 & 126974 & 105559 & 105556 & 187621 \\
\hline & $\mathrm{df}$ & 767 & 767 & 191 & 191 & 191 & 191 \\
\hline & $\mathrm{MS}$ & 822 & 822 & 191 & 552 & 552 & 982 \\
\hline \multicolumn{2}{|l|}{$F$} & 6.27 & 50.77 & 3.61 & 1.96 & 4.3 & 0.21 \\
\hline \multicolumn{2}{|c|}{ Prob $>F$} & 0.002 & 0 & 0.0288 & 0.1432 & 0.015 & 0.8069 \\
\hline \multirow{2}{*}{ 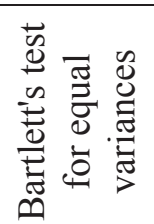 } & $\mathrm{Chi}^{2}$ & 6.64 & 22.28 & 16.56 & 6.49 & 5.3 & 0.14 \\
\hline & $\begin{array}{l}\text { Prob } \\
>\text { chi }^{2}\end{array}$ & $\begin{array}{l}\operatorname{chi}^{2}(2) \\
=0.036\end{array}$ & $\operatorname{chi}^{2}(3)=0$ & $\operatorname{chi}^{2}(2)=0$ & $\begin{array}{l}\operatorname{chi}^{2}(2) \\
=0.039\end{array}$ & $\begin{array}{l}\operatorname{chi}^{2}(2) \\
=0.071\end{array}$ & $\begin{array}{l}\operatorname{chi}^{2}(2) \\
=0.93\end{array}$ \\
\hline
\end{tabular}

TABLE 4

PAIRED T-TESTS

\begin{tabular}{|c|c|c|c|c|c|c|c|c|c|}
\hline \multicolumn{2}{|c|}{$\begin{array}{l}\text { Rounds \& } \\
\text { Treatments }\end{array}$} & \multirow{2}{*}{$\begin{array}{c}\text { Diff. } \\
18.09\end{array}$} & \multirow{2}{*}{$\begin{array}{c}\text { SD } \\
5.10\end{array}$} & \multirow{2}{*}{$\begin{array}{c}\text { T-value } \\
3.55\end{array}$} & \multirow{2}{*}{$\begin{array}{c}\begin{array}{c}\mathrm{H}_{\mathrm{a}}: \text { mean } \\
(\mathrm{Diff})<0\end{array} \\
0.9996\end{array}$} & \multirow{2}{*}{$\begin{array}{c}\mathrm{H}_{\mathrm{a}}: \text { mean } \\
(\mathrm{Diff})=0 \\
0.0007\end{array}$} & \multirow{2}{*}{$\begin{array}{c}\begin{array}{c}\mathrm{H}_{\mathrm{a}}: \text { mean } \\
(\mathrm{Diff})>0\end{array} \\
0.0004\end{array}$} & \multicolumn{2}{|c|}{$\begin{array}{c}\text { 95\% Conf. } \\
\text { Interval (Diff) }\end{array}$} \\
\hline$n$ & R1 - R2 & & & & & & & 7.90 & 28.29 \\
\hline$\Xi$ & $\mathrm{R} 2$ - R3 & 17.56 & 4.18 & 4.20 & 1.0000 & 0.0001 & 0.0000 & 9.20 & 25.92 \\
\hline 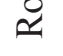 & R1 - R3 & 35.65 & 7.93 & 4.50 & 1.0000 & 0.0000 & 0.0000 & 19.81 & 51.48 \\
\hline \multirow{6}{*}{ 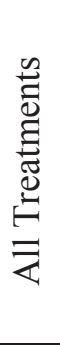 } & $\mathrm{T} 1-\mathrm{T} 2$ & -7.42 & 4.93 & -1.50 & 0.0686 & 0.1371 & 0.9314 & -17.26 & 2.43 \\
\hline & $\mathrm{T} 2-\mathrm{T} 3$ & -38.04 & 8.83 & -4.30 & 0.0000 & 0.0001 & 1.0000 & -55.68 & -20.40 \\
\hline & $\mathrm{T} 3-\mathrm{T} 4$ & -42.63 & 10.93 & -3.90 & 0.0001 & 0.0002 & 0.9999 & -64.47 & -20.78 \\
\hline & $\mathrm{T} 1-\mathrm{T} 3$ & -45.46 & 9.23 & -4.92 & 0.0000 & 0.000 & 1.0000 & -63.90 & -27.01 \\
\hline & $\mathrm{T} 1$ - T4 & -88.08 & 11.78 & -7.50 & 0.0000 & 0.0000 & 1.0000 & -111.61 & -64.55 \\
\hline & $\mathrm{T} 2-\mathrm{T} 4$ & -80.67 & 12.12 & -6.65 & 0.0000 & 0.0000 & 1.0000 & -104.89 & -56.44 \\
\hline \multirow{3}{*}{ 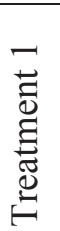 } & $\mathrm{R} 1-\mathrm{R} 2$ & 4.32 & 2.21 & 1.96 & 0.9726 & 0.0548 & 0.0274 & .09 & 8.74 \\
\hline & R1 - R3 & 11.94 & 3.13 & 3.82 & 0.9998 & 0.0003 & 0.0002 & 5.69 & 18.18 \\
\hline & R1-R2 & 7.62 & 2.27 & 3.36 & 0.9993 & 0.0013 & 0.0007 & 3.09 & 12.14 \\
\hline
\end{tabular}




\begin{tabular}{|c|c|c|c|c|c|c|c|c|c|}
\hline \multicolumn{2}{|c|}{$\begin{array}{l}\text { Rounds \& } \\
\text { Treatments }\end{array}$} & \multirow{2}{*}{$\begin{array}{l}\text { Diff. } \\
4.60\end{array}$} & \multirow{2}{*}{$\begin{array}{l}\text { SD } \\
1.92\end{array}$} & \multirow{2}{*}{$\begin{array}{c}\text { T-value } \\
2.40\end{array}$} & \multirow{2}{*}{$\begin{array}{c}\mathrm{H}_{\mathrm{a}}: \text { mean } \\
(\mathrm{Diff})<0\end{array}$} & \multirow{2}{*}{$\begin{array}{c}\mathrm{H}_{\mathrm{a}}: \text { mean } \\
(\mathrm{Diff})=0 \\
0.0195\end{array}$} & \multirow{2}{*}{$\begin{array}{c}\mathrm{H}_{\mathrm{a}}: \text { mean } \\
(\mathrm{Diff})>0\end{array}$} & \multicolumn{2}{|c|}{$\begin{array}{l}\text { 95\% Conf. } \\
\text { Interval (Diff) }\end{array}$} \\
\hline $\mathrm{N}$ & $\mathrm{R} 1-\mathrm{R} 2$ & & & & & & & .77 & 8.45 \\
\hline $\overrightarrow{0}$ & R2 - R3 & 4.79 & 1.46 & 3.29 & 0.9992 & 0.0017 & 0.0008 & 1.88 & 7.70 \\
\hline 苞 & R1 - R3 & 3.56 & 1.38 & 2.60 & 0.9940 & 0.0121 & 0.0060 & .81 & 6.32 \\
\hline \multirow{3}{*}{ 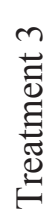 } & $\mathrm{R} 1-\mathrm{R} 2$ & 7.11 & 2.15 & 3.31 & 0.9992 & 0.0015 & 0.0008 & 2.82 & 11.41 \\
\hline & R2 - R3 & 4.79 & 1.52 & 3.29 & 0.9992 & 0.0017 & 0.0008 & 1.88 & 7.70 \\
\hline & R1 - R3 & 11.90 & 2.97 & 3.40 & 0.9999 & 0.0002 & 0.0001 & 5.98 & 17.83 \\
\hline \multirow{3}{*}{ 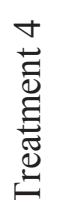 } & $\mathrm{R} 1-\mathrm{R} 2$ & 2.05 & 1.52 & 1.35 & 0.9092 & 0.1817 & 0.0908 & -.98 & 5.08 \\
\hline & $\mathrm{R} 2$ - R3 & 1.59 & 1.86 & 0.85 & 0.8012 & 0.3975 & 0.1988 & -2.14 & 5.31 \\
\hline & R1 - R3 & 3.64 & 2.84 & 3.40 & 0.2056 & 0.1028 & 0.0001 & -2.05 & 0.90 \\
\hline
\end{tabular}

TABLE 5

COMPARISON OF WEALTH BY TREATMENT

\begin{tabular}{|c|c|c|c|}
\hline \multicolumn{4}{|c|}{ (Bonferroni) } \\
\hline $\begin{array}{c}\text { Row } \\
\text { Mean- } \\
\text { Col } \\
\text { Mean }\end{array}$ & T1 & T2 & T3 \\
\hline T2 & $\begin{array}{c}6.15 \\
(0.133)\end{array}$ & & \\
\hline T3 & $\begin{array}{c}15.15 \\
(0.000)\end{array}$ & $\begin{array}{c}9.00 \\
(0.000)\end{array}$ \\
\hline T4 & $\begin{array}{c}29.36 \\
(0.000)\end{array}$ & $\begin{array}{c}23.21 \\
(0.000)\end{array}$ & $\begin{array}{c}14.21 \\
(0.000)\end{array}$ \\
\hline
\end{tabular}

TABLE 6

COMPARISON OF WEALTH BY ROUND

\begin{tabular}{|c|c|c|}
\hline \multicolumn{3}{|c|}{ (Bonferroni) } \\
\hline $\begin{array}{c}\text { Row Mean- } \\
\text { Col Mean }\end{array}$ & R1 & R2 \\
\hline R2 & $\begin{array}{c}-4.52 \\
(0.215)\end{array}$ \\
\hline R3 & $\begin{array}{c}-6.16 \\
(0.043)\end{array}$ & $\begin{array}{c}-1.63 \\
(1.000)\end{array}$ \\
\hline
\end{tabular}

The intuition behind Table 4 is consistent with behavioral norms. Higher tax rates reduce wealth disclosure. The annotations R1,R2 and R3 indicate the totality of all Rounds 1,2 and 3 respectively. The mean value implies the difference in average wealth disclosure among the sessions tested. The estimation shows higher tax rates create a reduction in wealth disclosure at the $0.1 \%$ significance level. Studies such as Crane \& Nourzad (1990) similarly concludes that tax evaders increase tax evasion attempts in response to higher tax rates. One of the main contributors of taxpayers' reaction to tax evasion is the tax rate (Freire-Serén \& Panadés, 2013). A study of tax evasion in China by Fisman \& Wei (2001) found tax evasion elasticity increases with an increased level of tax and on average, a 1 percent increase in the tax rate results in a 3 percent increase in evasion. Thus, this analysis is not only consistent with our hypothesis but also with the general consensus in the literature that says higher taxes reduce wealth disclosure.

The average Treatment wealth disclosure also bodes well with our second hypothesis, as the results clearly show wealth disclosure has a statistically significant reduction with each riskier Treatment. Therefore, when the possibility of audit and bribe are factored in, the wealth disclosure decreases. Moreover, the riskiest treatment, Treatment 4 shows the highest levels of wealth disclosure. In other 
words, when the risk of being audited is factored in and the risk of punishment for hiding wealth increases, the wealth disclosure increases in response, as evident by the statistically significant positive difference in wealth disclosure from each progressive treatment.

Finally, Table 4 also shows the levels and significant differences in wealth disclosure within each Treatment. Similar to the previous average patterns, the estimation from the series of t-tests indicates that generally speaking, wealth disclosure increases when we chronologically move down the Treatments. The findings bode well with rational optimization as the payoff maximizing ethos would dictate participants should be aiming to balance risk with the expected payoff. Participants respond with options that maximize their payoff without regard for the moral connotations that come with wealth disclosure and paying a bribe. It is reasonable to assume such behavior is replicated in the real world thus accounting for lower tax collection in countries that do not have a strong framework of checks and balances. If we are to rely on the guidance of rational optimization, the fact that participants disclose less wealth when given the opportunity ultimately hints that the average taxpayer contemplates the risk payoff matrix.

Not only do wealth disclosures of each treatment follow a logical pattern, but it is also consistent with the fact that in all treatments, wealth disclosure keeps decreasing as the participants move up the higher tax Rounds. Treatment 1 was the most riskless, followed by Treatment 2 which also had a riskless component due to the option of mitigating punishment by paying a bribe. Treatment 3 becomes riskier in terms of hiding wealth as the bribe was only payable before wealth disclosure. Treatment 4 leaves little wiggle room to mitigate any sort of risk. Moreover, the difference in wealth disclosure between each treatment is highly significant implying the wealth disclosure of participants are consistent. The fact that the risk of audit and punishment plays a vital role in the decision making of wealth disclosure suggests these decisions are not random. When Dubin \& Wilde (1988) presented empirical evidence on the relationship between tax compliance and auditing by the Internal Revenue Service (IRS) in the United States, they found support for an economic approach to tax compliance that incorporates the IRS as a strategic actor. Moreover, after allowing for the simultaneous determination of audit rates and compliance levels, they find significant deterrent effects of auditing on noncompliance. Similar to our own estimation, Pommerehne \& Weck-Hannemann (1996) found tax noncompliance has a positive relationship with marginal tax burden whereas it has a negative relationship with the probability of audit. Morevoer, Birskyte (2013) concluded that an increase in audit rates increase tax compliance among individuals. The fact that audit acts as a deterrent to wealth non-disclosure is not difficult to grasp, as Modugu \& Anyaduba (2014) describes, although taxpayers' compliance towards tax obligations can be attributed to reasons other than an increased probability of audit, audits directly affect certain segments of tax returns. This behavior is not only expected but is consistent with literature that delved into similar studies. The combined effect of fines and high audit rates heavily impact tax compliance (Alm et al., 1995). Tables 5,6 and 7 show a version of multiple comparisons test using a Bonferroni test. It computes a pairwise comparison that adjusts for multiple Bonferroni corrections. The p-value is also adjusted for the Bonferroni correction. The estimations from the Bonferroni pairwise comparisons more or less adheres to the same statistical pattern computed from the T-tests. 


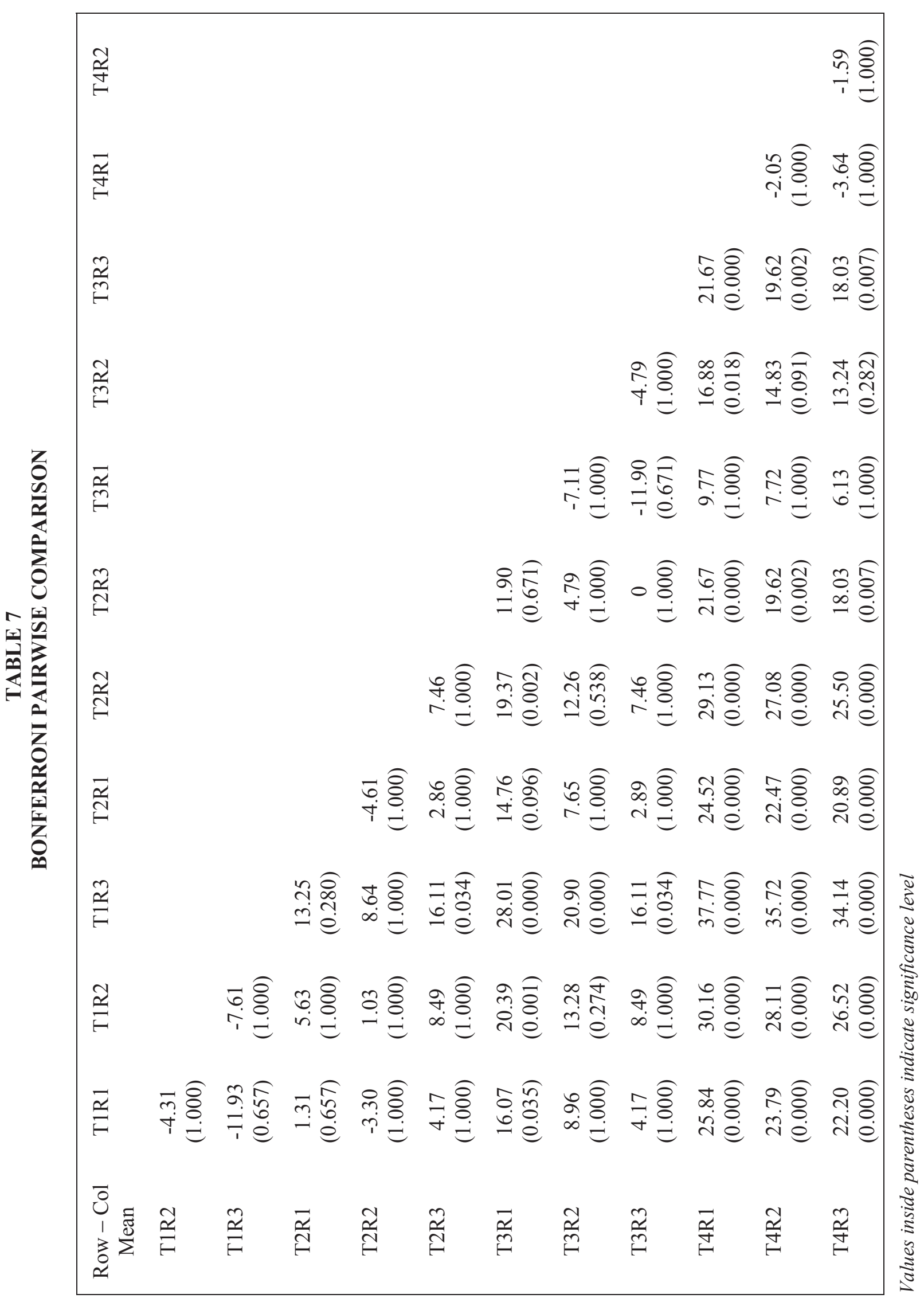

Journal of Applied Business and Economics Vol. 22(2) 2020131 
As far as complying with tax goes, participants seem to hold no reservations about the ethical conundrum that come with tax evasion. If the payoff can be maximized, wealth is under-reported. Tax evasion cannot be fully understood without the context of social aspects. Social norms might have a strong impact on an individual's ethical values. Social customs and moral beliefs are the two determinants of one's tax compliance according to a study conducted by Wenzel (2005) in Australia. This is a combination of the intrinsic value that comes within and the intrinsic value deriving from crowd behavior (Cullis et al., 2012). Since complying with social norms often come with personal costs, in the absence of any punishment individuals might decide to violate social norms in the pursuit of private gains. In addition, Kiow et al. (2017) noticed that an individual's tax compliance behavior tends to show an increase if that person's primary group members comply with tax rulebooks. This is especially relevant in the context of Bangladesh as trust in public bodies has all but collapsed (Knox, 2009).

\section{CONCLUSION}

The theoretical experiment game design proposed by this study set out to investigate the tax evasion behavior of participants in Bangladesh. This study is unique in relation to previous studies that focused on tax issues in Bangladesh. The literature does not have a tax experiment game specifically designed for the context of Bangladesh. In particular, this research investigated individuals' behavior when they had an incentive to partake in corruption by evading taxes and paying bribes. This study examined whether wealth disclosure is significantly different when the tax rate and the risk of audit and punishment changes. The estimations indicate there is a predictable pattern of income reporting consistent with the general consensus in the existing literature. The data seem to suggest rational players are well aware of payoff optimization by contemplating the risk, punishment and payoff. Specifically, higher tax rates lead to lesser income disclosure thereby contributing to tax evasion behavior. On the contrary, the risk of audit and punishment leads to higher income disclosure. Individuals' tax evasion behavior in this experiment can partly be explained by payoff maximization as individuals weighed between risk and expected payoff before disclosing their income.

Corruption and tax avoidance are two unique, yet interrelated problems that should not be considered independently when it comes to the government revenue collection systems (Alm et al., 2016). The findings of this study have implications for the government's tax-related policies and programs especially in the context of Bangladesh. It is one of the most corrupt countries in the world ranking 149 among 180 countries (Transparency International, 2018). Widespread pervasive corruption has led to a culture of impunity in Bangladesh (Rahman, 2019). The government of Bangladesh has formulated several policies and developed various strategies to strengthen its anti-corruption drives against tax evasion. Some notable initiatives by NBR have resulted in increased tax revenue collection in recent years. However, corruption is so prevalent in Bangladesh that mere planning and executing strategies without studying the behavioral aspects of tax evasion may not prove to be effective. Policymakers need to consider corruption and individuals' behavior while developing strategies and action plans to make the people of Bangladesh more tax compliant.

Replicating a real-world scenario of tax evasion in an experimental setting is difficult, as individuals' behavior is heavily influenced by exogenous forces such as culture and innate goodness. The social and moral developments of individuals stem from societal norms and culture (Turiel, 2002). The need to conduct more research to assimilate tax compliance behavioral inconsistencies cannot be stressed enough. Further research on the relationship between tax evasion and tax rates is required as there are many gaps in the existing literature (Freire-Serén \& Panadés, 2013). Corruption and tax evasion can be remedied with good governance in tax administration (Uslaner, 2010).

\section{ENDNOTES}

1. As of 14 November 2019, 1 USD is equivalent to BDT 84.75 (Finance.yahoo.com, 2019). 


\section{REFERENCES}

Abbink, K., Irlenbusch, B., \& Renner, E. (2002). An experimental bribery game. Journal of Law, economics, and organization, 18(2), 428-454.

Acconcia, A., D'amato, M. \& Martina,R. (2003). Corruption and tax evasion with competitive bribes. Centre for Studies in Economics and Finance Working Paper no.112. University of Salerno, Italy.

Ahmed, D. (2018). Tax Evasion in Bangladesh: Causes, Consequnces and Remedies. The Cost and Management, 46(2), 51-56.

Akdede, S. H. (2011). Corruption and tax evasion. Doğuş Üniversitesi Dergisi, 7(2), 141-149.

Allingham, M. G., \& Sandmo, A. (1972). Income tax evasion: A theoretical analysis. Journal of public economics, 1(3-4), 323-33

Alm, J., Martinez-Vazquez, J., \& McClellan, C. (2016). Corruption and firm tax evasion. Journal of Economic Behavior \& Organization, 124, 146-163.

Alm, J., McClelland, G. H., \& Schulze, W. D. (1992). Why do people pay taxes?. Journal of public Economics, 48(1), 21-38.

Alm, J., Sanchez, I., \& De Juan, A. (1995). Economic and noneconomic factors in tax compliance. Kyklos, 48(1), 1-18.

Barr, A., \& Serra, D. (2010). Corruption and culture: An experimental analysis. Journal of Public Economics, 94, 862-869.

Bhuiyan, M. Z. (2012). Tax Evasion and Avoidance Practices in Some Selected Corporate Firms of Bangladesh. World Journal of Social Sciences, 2(7), 150-156.

Birskyte, L. (2013). Effects of Tax Auditing: Does the deterrent deter? Research Journal of Economics, Business and ICT, 8(2), 1-8.

Bordignon, M. (1993). A fairness approach to income tax evasion. Journal of Public Economics, 52(3), 345-362.

Chowdhury, S. T. (2015). Is Bangladeshi Professionals' Tax-Paying Behavior in Convergence with the Principles of Taxation?. Research in World Economy, 6(3), 55.

Crane, E. S., \& Nourzad, F. (1990). Tax Rates and Tax Evasion: Evidence From California. National Tax Journal, 43(2), 189-99.

Crocker, K. J., \& Slemrod, J. (2005). Corporate tax evasion with agency costs. Journal of Public Economics, 89(9-10), 1593-1610

Cullis, J., Jones, P., \& Savoia, A. (2012). Social norms and tax compliance: Framing the decision to pay tax. The Journal of Socio-Economics, 41(2), 159-168.

Cummings, R. G., Vazquez, J. M., McKee, M., \& Torgler, B. (2005). Effects of Tax Morale on Tax Compliance:Experimental and Survey Evidence (NCER Working Paper Series No. 12).

Dong, B., Dulleck, U., \& Torgler, B. (2012). Conditional corruption. Journal of Economic Psychology,33, 609-627.

Dubin, J. A., \& Wilde, L. L. (1988). An empirical analysis of federal income tax auditing and compliance. National tax journal, 61-74.

Fenochietto, M. R., \& Pessino, M. C. (2013). Understanding countries' tax effort (No. 13-244). International Monetary Fund.

Finance.yahoo.com. (2019). [online] Available at: https://finance.yahoo.com/quote/USDBDT=X?1tr=1 [Accessed 14 Nov. 2019].

Fisman, R., \& Wei, S.-J. (2001). Tax rates and Tax Evasion: Evidence from "Missing Imports" in China. NBER Working Paper 8551.

Flatters, F., \& Macleod, W. B. (1995). Administrative corruption and taxation. International Tax and Public Finance, 2(3), 397-417.

Freire-Serén, M. J., \& Panadés, J. (2013). Do Higher Tax Rates Encourage/Discourage Tax Compliance? Modern Economy, 4(12), 809-817. 
Goerke, L., \& Runkel, M. (2006). Profit tax evasion under oligopoly with endogenous market structure. National Tax Journal, 851-857.

Hofmann, E., Hoelzl, E., \& Kirchler, E. (2008). Preconditions of voluntary tax compliance: Knowledge and evaluation of taxation, norms, fairness, and motivation to cooperate. Zeitschrift für Psychologie/Journal of Psychology, 216(4), 209-217.

Jellal, Mohamed and Mohamed Bouzahzah. "Corruption and Tax Evasion: An Optimal Policy." MPRA Paper No. 38813. Munich, Germany: 2012.

Joulfaian, D. (2009). Bribes and business tax evasion. European Journal of Comparative Economics, 6(2), 227-244.

Kiow, T. S., Salleh, M. F. M., \& Kassim, A. A. B. M. (2017). The determinants of individual taxpayers' tax compliance behaviour in peninsular malaysia. International Business and Accounting Research Journal, 1(1), 26-43.

Knox, C. (2009). Building trust amidst corruption in Bangladesh. The Round Table, 98(403), 449-459.

Kubbe, I., \& Engelbert, A. (Eds.). (2017). Corruption and Norms: Why Informal Rules Matter. Springer

Lim, T. S., \& Loh, W. Y. (1996). A comparison of tests of equality of variances. Computational Statistics \& Data Analysis, 22(3), 287-301.

Long, D. M., \& Rao, S. (1995). The wealth effects of unethical business behavior. Journal of Economics and Finance, 19(2), 65-73.

Mahmood, S. A. (2010). Public procurement and corruption in Bangladesh confronting the challenges and opportunities. Journal of public administration and policy research, 2(6), 103-111.

Mauro, P. 1998. Corruption and the composition of government expenditure. Journal of Public Economics, 69, 263-267.

McGee, R., Aljaaidi, K. S., \& Musaibah, A. S. (2012). The Ethics of Tax Evasion: A Survey of Administrative Sciences' Students in Yemen. International Journal of Business and Management, 7(16), 1

McGee, R., Devos, K., \& Benk, S. (2016). Attitudes towards tax evasion in Turkey and Australia: A comparative study. Social Sciences, 5(1), 10.

Modugu, K. P., \& Anyaduba, J. O. (2014). Impact of tax audit on tax compliance in Nigeria. International journal of business and social science, 5(9), 207-215.

Mohdali, R., Isa, K., \& Yusoff, S. H. (2014). The impact of threat of punishment on tax compliance and non-compliance attitudes in Malaysia. Procedia-Social and Behavioral Sciences, 164, 291-297.

Nawaz, F. (2010). Exploring the Relationships between Corruption and Tax Revenue. Transparency International.

Nurunnabi, M. (2019). Tax Evasion and the Role of the State Actor(s) in Bangladesh. International Journal of Public Administration, 42(10), 823-839.

Okoye, P. V., Akenbor, C. O., \& Obara, L. C. (2012). Promoting sustainable tax compliance in the informal sector in Nigeria. AFRREV IJAH: An International Journal of Arts and Humanities, $1(1), 40-54$.

Olken, B. A., \& Pande, R. (2012). Corruption in developing countries. Annu. Rev. Econ., 4(1), 479-509.

Pommerehne, W. W., \& Weck-Hannemann, H. (1996). Tax rates, tax administration and income tax evasion in Switzerland. Public Choice, 88,161 - 170.

Rahman, K. (2019). Overview of corruption and anti-corruption in Bangladesh. Transparency International.

Report, S. (2019). Majority don't pay income tax: NBR. Retrieved 27 October 2019, from https://www.thedailystar.net/business/economy/income-tax-return-in-bangladesh-majority-dontpay-1779688

Saada, N. (2012). Tax Non-Compliance Behaviour: Taxpayers View. Procedia - Social and Behavioral Sciences, 65, $344-351$.

Sen, D. K., \& Bala, S. K. (2002). Tax audit: Bangladesh panorama. Managerial Auditing Journal, 17(8), 464-477.

134 Journal of Applied Business and Economics Vol. 22(2) 2020 
Snedecor, G. W., \& Cochran, W. G. (1989). Statistical methods, 8thEdn. Ames: Iowa State Univ. Press Iowa.

Svensson, J. (2005). Eight questions about corruption. Journal of economic perspectives, 19(3), 19-42.

Transparency International. (2018) Corruption Perceptions Index 2018. Retrieved 8 November 2019, from https://www.transparency.org/cpi2018

Turiel, E. (2002). The culture of morality: Social development, context, and conflict. Cambridge University Press.

United Nations. (2019). World Economic Situation and Prospects. New York.

Uslaner, E. M. (2010). Tax evasion, corruption, and the social contract in transition. Developing alternative frameworks for explaining tax compliance, 59, 174.

Wang, L. F., \& Conant, J. L. (1988). Corporate tax evasion and output decisions of the uncertain monopolist. National Tax Journal, 41(4), 579-581.

Wanniski, J. (1978). Taxes, revenues, and the Laffer curve. The Public Interest, 50, 3.

Wenzel, M. (2005). Motivation or rationalisation? Causal relations between ethics, norms and tax compliance. Journal of Economic Psychology, 26(4), 491-508.

Wickberg, S., Chene, M., \& Zinnbauer, D. (2012). Overview of corruption and anti-corruption in Bangladesh. Report by Transparency International.

World Bank (1997). Helping Countries Combat Corruption: The Role of the World Bank. Retrieved from http://www1.worldbank.org/publicsector/anticorrupt/corruptn/cor02.htm

World Bank (2019). Bangladesh Development Update: Towards regulatory predictability. Dhaka, Bangladesh. 


\section{APPENDIX}

The analysis of variance for all the sub-categories of Table 3 can be better understood with the breakdown of the mean tested null and alternative hypothesis.

TABLE 8

ANALYSIS OF VARIANCE (ANOVA) HYPOTHESES OF ROUNDS AND TREATMENTS

\begin{tabular}{|c|c|}
\hline Rounds & Treatments \\
\hline $\begin{array}{c}\mathrm{H}_{0}: \mu_{\mathrm{R} 1}=\mu_{\mathrm{R} 2}=\mu_{\mathrm{R} 3} \\
\mathrm{H}_{1}: \mu_{\mathrm{Ri}} \neq \mu_{\mathrm{Ri}}\end{array}$ & $\begin{array}{c}\mathrm{H}_{0}: \mu_{\mathrm{T} 1}=\mu_{\mathrm{T} 2}=\mu_{\mathrm{T} 3}=\mu_{\mathrm{T} 4} \\
\mathrm{H}_{1}: \mu_{\mathrm{Ti}} \neq \mu_{\mathrm{Ti}}\end{array}$ \\
\hline \multicolumn{2}{|c|}{$\mathrm{i}^{\text {th }}$ Treatment } \\
\hline \multicolumn{2}{|c|}{$\mathrm{H}_{0}: \mu_{\mathrm{T} 1 \mathrm{R} 1}=\mu_{\mathrm{T} 1 \mathrm{R} 2}=\ldots \ldots . .}$. \\
$\mathrm{H}_{1}: \mu_{\mathrm{TiRi}} \neq \mu_{\mathrm{T} \mathrm{Ri}}$ \\
\hline
\end{tabular}

The null hypothesis is that the means of all categories of Treatment or Round as defined in Table 8 are equal. The opposing alternative hypothesis is a simple refutation of this equality assumption where at least one of the means are not equal. For the most part, low p-value has led to the rejection of the null hypothesis.

FIGURE 2

BOX WHISKER PLOT BY TREATMENTS AND ROUNDS

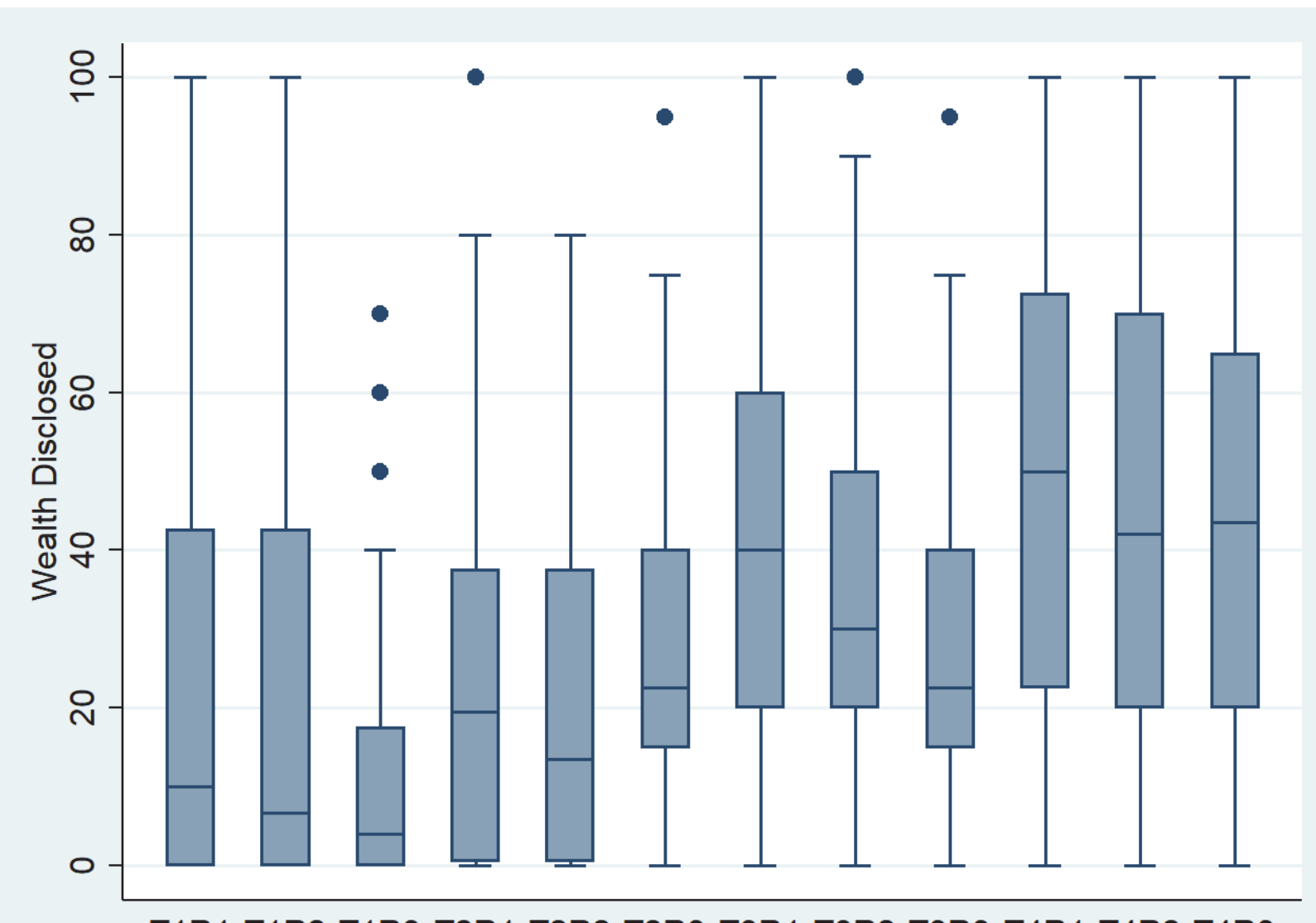

T1R1 T1R2 T1R3 T2R1 T2R2 T2R3 T3R1 T3R2 T3R3 T4R1 T4R2 T4R3 